Philippe Montravers

Hervé Dupont

Jean-Pierre Bedos

Philippe Bret

The Tigecycline Group

\title{
Tigecycline use in critically ill patients:
a multicentre prospective observational study \\ Tigecycline use in critically ill patients: in the intensive care setting
}

Received: 28 January 2014

Accepted: 25 April 2014

Published online: 29 May 2014

(C) The Author(s) 2014. This article is published with open access at

Springerlink.com

Take-home message: The efficacy and safety of tigecycline in the treatment of severe infections is consistent with other antibiotics, regardless of disease severity. No particular safety concerns were raised.

A related editorial can be found at doi: 10.1007/s00134-014-3343-3.

\section{Electronic supplementary material} The online version of this article (doi:10.1007/s00134-014-3323-7) contains supplementary material, which is available to authorized users.

\section{P. Montravers ( $)$}

Department of Anesthesiology and Surgical Intensive Care, Bichat-Claude Bernard University Hospital Center, Paris Diderot University, Sorbonne Paris-Cité and APHP, 46 Rue Henri-Huchard, 75018 Paris, France

e-mail: philippe.montravers@bch.aphp.fr Tel.: +33140258355

\section{H. Dupont}

Department of Anesthesia and Critical Care Medicine, Amiens University Hospital Center, University of Picardie Jules Verne,
Amiens, France

e-mail: dupont.herve@chu-amiens.fr

\section{J.-P. Bedos}

Department of Intensive Care, André Mignot Hospital, Versailles, France e-mail: jpbedos@ch-versailles.fr

\section{P. Bret}

Pfizer France, Paris, France

e-mail: Philippe.Bret@pfizer.com

Abstract Purpose: This prospective observational study aimed at describing prescription patterns of tigecycline and patient outcomes in 26 French intensive care units (ICU). Methods: Data of consecutive cases of adult patients treated with tigecycline were collected from the initiation until 7 days after the end of treatment. Response to treatment was classified as success, failure or undetermined and analyses were presented according to severity (SOFA score $<7$ or $\geq 7$ ). Survival was recorded at 28 days. Results: A total of 156 patients were included (64\% male, age $60 \pm 15$ years). At inclusion, $53 \%$ had a SOFA score $\geq 7 ; 93 \%$ had received prior anti-infective agents. Tigecycline was given as first-line treatment in $47 \%$ of patients, mostly in combination (67\%), for intra-abdominal (IAI $56 \%$ ), skin and soft tissue (SSTI $19 \%$ ) or other infections. A total of $76 \%$ of the treated infections were hospital-acquired. Bacteraemia was reported in $12 \%$ of patients. Median treatment duration was 9 days. Tigecycline was prematurely stopped in $42 \%$ patients. The global success rate was $60 \%$ at the end of treatment, and significantly higher with treatment duration more than 9 days (76 vs. $47 \%, P<0.001)$. Success rate was $65 \%$ for patients alive at the end of treatment. Success rates tended to decrease with illness severity, immunosuppression, bacteraemia and obesity. Survival rate at day 28 was $85 \%$ in the whole cohort and significantly higher in the less severely ill patients $(P<0.001)$. Conclu-

sions: Tigecycline success rates appear comparable to those reported in clinical studies in ICU with severe infections. Tigecycline could be an alternative in ICU patients.

Keywords Tigecycline . Multidrug resistance $\cdot$ Intensive care . Organ failure $\cdot$ Severe infections

\section{Introduction}

Tigecycline is one of the scarce available compounds, with a broad-spectrum activity, effective against multidrug-resistant strains including Gram-positive, Gram-negative aerobic, anaerobic bacteria and atypical microorganisms. In randomised controlled trials (RCT), tigecycline was effective in the treatment of complicated 
skin and soft tissue infections (cSSTIs) [1-3], complicated intra-abdominal infections (cIAIs) [4-7] and community-acquired pneumonia (CAP) [8-10]. Additional studies showed that tigecycline was effective in serious infections caused by known resistant pathogens $[11,12]$.

However, the use of tigecycline in patients with severe underlying diseases is limited, and little is known about its efficacy [13-15]. To date, RCTs included few intensive care unit (ICU) patients. Few data are available for ICU patients with bacteraemia [16].

For these reasons, we carried out a prospective, observational study in the intensive care setting to describe tigecycline prescription patterns and outcomes in critically ill patients from French ICUs. Some of our results were recently published in a series of articles reporting the "real-life" practice gathering five European databases (German, Italian, two Spanish studies and the current cohort). These analyses focused on labelled indications [17-19], global microbiology results [20] and safety issues [21], but did not address several key points, such as off-label indications, bacteraemia, emergence of resistance, superinfections and long-term outcomes; this led us to consider this in-depth analysis.

\section{Materials and methods}

Study design and patients

This prospective, multicentre, national observational study included consecutive cases of adult ICU patients treated with tigecycline. The only inclusion criterion was the receipt of tigecycline therapy in any, approved or nonapproved, indication as mono- or combination, empiric, documented or rescue therapy for a specific localised source of infection or a specific flora. There was no recommendation on dosage or needed indication for the study protocol.

In accordance with French law, approval of an ethics committee was not required. The protocol was approved by the institutional review board (CEERB, CHU Bichat, Paris). All patients were informed of the data collection and agreed to participate in the study. A scientific committee (the authors) independently designed the study and reviewed all the collected data.

\section{Clinical and microbiological data}

Data were collected at ICU admission, at the start and end of tigecycline treatment, and 7 days after the end of treatment (or at hospital discharge if earlier). Clinical data included demographics, underlying diseases [22] (including diabetes mellitus, chronic renal failure, and chronic liver failure assessed using the Child-Pugh score [23]), immunosuppression (defined as steroid therapy or cancer therapy), severity of illness (assessed using the simplified acute physiology score (SAPS) II at ICU admission [24] and the sequential organ failure assessment (SOFA) score at the start of tigecycline treatment [25]), and previous tigecycline therapy.

The tigecycline-treated infection was clinically and microbiologically characterised. cIAIs (localised, generalised peritonitis, etc.) and cSSTI (dermis-hypodermis, fascia, etc.) were detailed as assessed during the surgery. The infection site and hospital- or community-acquired settings were collected.

The results of direct examinations and cultures were recorded. Identification and in vitro sensitivity testing of the pathogens were performed in the microbiology laboratory of each hospital using routine methods. Isolates were classified as susceptible (S), intermediate (I) or resistant (R) to tigecycline according to European Committee on Antimicrobial Susceptibility Testing (EUCAST) methodology. Data concerning persistent and emerging isolates, including Pseudomonas aeruginosa, were collected.

\section{Treatment data}

The reasons for choosing tigecycline and any anti-infective agents received in the previous 28 days were recorded. The tigecycline regimen (loading dose, maintenance dose and treatment duration) and the associated anti-infective agents were recorded.

\section{Outcomes}

Response to treatment was determined as clinical success/ failure at the end of tigecycline treatment and 7 days later (or at hospital discharge if earlier). Success was defined by the lack of need to use a new antibiotic or a surgical treatment not initially planned for the initial infection. Criteria for failure were persistence of the initial infection signs requiring a change of antibiotic therapy or a surgical intervention, reappearance of the initial infection signs, infection-related death occurred later than $48 \mathrm{~h}$ after the start of tigecycline and/or premature treatment discontinuation due to a tigecycline-related adverse event. Response was classified as undetermined in case of insufficient data (e.g. de-escalation before the fourth day of treatment), death not directly related to the initial infection or occurred within the first $48 \mathrm{~h}$ of treatment, or addition of an antibacterial agent for another infection. Survival was recorded 28 days after the end of tigecycline treatment: data were retrieved from the French national epidemiology center for medical causes of death (CépiDc, 
Centre d'épidémiologie sur les causes médicales de décès, INSERM).

\section{Statistics}

Data were analysed using SAS ${ }^{\circledR} 8.2$ (SAS Institute Inc., Cary, NC, USA). To describe a characteristic or an event with a $10 \%$ frequency and an accuracy of $\pm 5 \%$ as assessed by the $95 \%$ confidence interval (95\% CI), 150 patients were to be enrolled.

For the purpose of this study, patients' characteristics were stratified for disease severity assessed by SOFA score $(<7$ or $\geq 7)$. Outcomes were stratified for SOFA score, body mass index (BMI $\leq 35 \mathrm{~kg}$ and $>35 \mathrm{~kg} / \mathrm{m}^{2}$ ), immunosuppression, and age groups ( $<70$ and $\geq 70$ years of age).

Variables were expressed as median values and ranges for numerical variables, and as frequencies and percentages for categorical variables. The $95 \%$ CIs of the response rates were calculated. Groups were compared using Wilcoxon signed-rank test for numerical variables, and the Chi square or the Fisher's exact test for categorical variables. Comparisons for success rates were carried out under the worse assumption, i.e. considering undetermined responses as failures. Factors independently associated with success to treatment at 7 days were identified by multivariate stepwise logistic regression among the factors that were statistically significant at the $10 \%$ level in univariate regressions and taking into account significant interactions. The predictive performance of the final multivariate model was evaluated using receiver operating characteristic (ROC) analysis [26]. Survival, defined as the time from the first tigecycline intake to 28 days after last intake (or death), whichever occurs first, was assessed using the Kaplan-Meier method. A log-rank test was performed for subgroup analyses. As day-28 follow-up was not available for 18 patients, their survival time was censored at the time of the last visit in the study. A death recorded after day 28 was censored at the time of day 28. Statistical significance was accepted at the $5 \%$ level.

\section{Results}

Patients' clinical characteristics

A total of 156 patients from 26 ICUs were enrolled between September 2008 and April 2010, including 73 patients with a SOFA score $<7$ and 83 severe cases (SOFA $\geq 7$ ) (Table 1$)$. Immunosuppression was mainly due to cancer $(n=29)$ and steroid therapy $(n=16)$.

The majority of patients (145/156, $93 \%$ ) had received one or more anti-infective agents in the last 30 days before the start of tigecycline [including penicillins (60\%), cephalosporins (42\%), aminoglycosides (39\%), carbapenems $(28 \%)$, glycopeptides $(26 \%)$ or fluoroquinolones $(26 \%)]$.

Infections treated with tigecycline

Tigecycline was given for the treatment of cIAI in 88/156 (56\%) patients, cSSTI in $29(19 \%)$ and other infections in $56(36 \%)$ (mainly lung infections, $n=38,24 \%$ ) (Table 1). Most of the treated infections were hospitalacquired $(131 / 173,76 \%)$. A positive blood culture was observed in $17(12 \%)$ patients. Overall, 17/145 (12\%) patients had secondary bacteraemia, including 9/63 $(12 \%)$ patients with a SOFA score $\geq 7(P=0.963)$. Indications for tigecycline were similar in the less and the most severely ill patients.

\section{Microbiological data}

Overall, $146(94 \%)$ patients had at least one microbiological sample at the start of tigecycline [direct examination in $87(56 \%)$ patients, species identified in $127(81 \%)$ patients] (Table 2). Infection was polymicrobial in 29 cases. There were no marked differences between the less and the most severely ill patients (data not shown).

Three microorganisms in three patients acquired resistance to tigecycline during the course of treatment (Escherichia coli, Enterobacter cloacae and Enterobacter aerogenes). Sixty-four microorganisms in 41 patients emerged during the course or at the end of treatment: 18 Gram-positive cocci (including 11 staphylococci), 39 Gram-negative bacilli (including $9 P$. aeruginosa, 6 Enterobacter ssp., 3 Proteus ssp., and 1 Morganella morganii), 4 anaerobic germs and 3 yeasts. A total of 28 microorganisms in 23 patients persisted with no change in susceptibility (both emergence and persistence were observed in 13 of these 23 patients) during the course of tigecycline treatment: 11 Gram-positive cocci (5 enterococci and 6 staphylococci) and 16 Gram-negative bacilli (including $6 \mathrm{E}$. coli, 4 Klebsiella spp. and 3 other enterobacteria).

\section{Treatment with tigecycline}

Characteristics of treatment are provided in Table 1. The vast majority of patients were given the recommended loading and maintenance doses with an overall median treatment duration of $9(1-78)$ days: $8(1-78)$ days in the less severely ill, 9 (2-43) days in the most severely ill $(P=0.499)$ patients and 9 days $(2-78)$ in patients alive at the end of treatment. Tigecycline was combined with other anti-infective agents in two-thirds of the patients (101/156, $65 \%$ ) (Fig. 1), without statistically significant 
Table 1 Treatment with tigecycline: patients' characteristics at baseline, types of infections treated and characteristics of treatment

\begin{tabular}{|c|c|c|c|c|}
\hline & $\begin{array}{l}\text { SOFA }<7 \\
n=73\end{array}$ & $\begin{array}{l}\text { SOFA } \geq 7 \\
n=83\end{array}$ & $\begin{array}{l}\text { Total } \\
n=156\end{array}$ & $P$ value \\
\hline \multicolumn{5}{|c|}{ Patients' clinical characteristics at the start of tigecycline treatment } \\
\hline \multicolumn{5}{|c|}{ Demographics } \\
\hline Age (years) & $61(19-84)$ & $63(27-86)$ & $62(19-86)$ & 0.268 \\
\hline Age $\geq 70$ years & $26 / 52(50)$ & $26 / 52(50)$ & $52 / 156(33)$ & 0.362 \\
\hline Male gender & $42 / 73(58)$ & $58 / 83(70)$ & $100 / 156(64)$ & 0.109 \\
\hline BMI $\left(\mathrm{kg} / \mathrm{m}^{2}\right)$ & $26(16-58)$ & $27(17-51)$ & $26(16-58)$ & 0.577 \\
\hline $\mathrm{BMI}>35 \mathrm{~kg} / \mathrm{m}^{2}$ & $7 / 64(11)$ & $10 / 78(13)$ & $17 / 142(12)$ & 0.731 \\
\hline \multicolumn{5}{|l|}{ Severity of disease } \\
\hline SAPS II on admission in ICU & $35(3-78)$ & $48(12-99)$ & $42(3-99)$ & $<0.001$ \\
\hline SOFA & $3(0-6)$ & $10(7-24)$ & $7(0-24)$ & $<0.001$ \\
\hline Hemodynamic failure & $4 / 73(6)$ & $12 / 83(15)$ & 16/156 (10) & \\
\hline Respiratory failure $^{\mathrm{a}}$ & $9 / 73(12)$ & $41 / 83(49)$ & $50 / 156(32)$ & \\
\hline Renal failure ${ }^{\mathrm{b}}$ & $2 / 73(3)$ & $26 / 83(31)$ & 28/156 (18) & \\
\hline \multicolumn{4}{|l|}{ Underlying disease } & 0.868 \\
\hline Ultimately fatal & 19/73 (26) & $21 / 82(26)$ & $40 / 155(26)$ & \\
\hline Rapidly fatal & $7 / 73(10)$ & $6 / 82(7)$ & $13 / 155(8)$ & \\
\hline Immunosuppression & $23 / 73(32)$ & $29 / 83(35)$ & $52 / 156(33)$ & 0.650 \\
\hline Diabetes mellitus & $12 / 73(16)$ & $18 / 83(22)$ & $30 / 156(19)$ & 0.771 \\
\hline Chronic renal failure & $4 / 73(5)$ & $12 / 83(15)$ & $16 / 156(10)$ & 0.110 \\
\hline Chronic liver failure & $1 / 73(1)$ & 4/83 (5) & $5 / 156(3)$ & 0.372 \\
\hline Prior anti-infective agents (last 30 days) & $68 / 73(93)$ & $77 / 83(93)$ & $145 / 156(93)$ & 0.926 \\
\hline \multicolumn{5}{|l|}{ Types of infections treated with tigecycline } \\
\hline Intra-abdominal infection & $37 / 73(51)$ & $51 / 83(61)$ & $88 / 156(56)$ & 0.176 \\
\hline Hospital-acquired & 26/37 (70) & $35 / 51(69)$ & $61 / 88(69)$ & \\
\hline Localised peritonitis & $7 / 26(27)$ & $3 / 42(7)$ & $10 / 68(15)$ & \\
\hline Abscess without peritonitis & $6 / 26(23)$ & $9 / 42(21)$ & $15 / 68(22)$ & \\
\hline \multicolumn{5}{|l|}{ Localisation } \\
\hline Colon & $15 / 37(41)$ & 25/51 (49) & $40 / 88(45)$ & \\
\hline Small intestine & $10 / 37(24)$ & $9 / 51(18)$ & $18 / 88(20)$ & \\
\hline Stomach/duodenum & $6 / 37(16)$ & $5 / 51(10)$ & $11 / 88(12)$ & \\
\hline Other site & $10 / 37(27)$ & $18 / 51(35)$ & $28 / 88(32)$ & \\
\hline Skin and soft tissues infection & $14 / 73(19)$ & $15 / 83(18)$ & 29/156 (19) & 0.859 \\
\hline Hospital-acquired & $10 / 14(71)$ & $10 / 15(67)$ & $20 / 29(69)$ & \\
\hline Dermohypodermitis & $13 / 14(93)$ & $15 / 15(100)$ & $28 / 29(97)$ & \\
\hline \multicolumn{5}{|l|}{ Localisation } \\
\hline Abdomen & $3 / 8(38)$ & 7/9 (78) & $10 / 17(59)$ & \\
\hline Head and neck & $4 / 8(50)$ & $1 / 9(11)$ & $5 / 17(29)$ & \\
\hline Other infection & $26 / 73(36)$ & $30 / 83(36)$ & $56 / 156(36)$ & 0.945 \\
\hline Hospital-acquired & $23 / 26(89)$ & $27 / 30(90)$ & $50 / 56(89)$ & \\
\hline Lung & $17 / 26(66)$ & $21 / 30(70)$ & $38 / 56(68)$ & \\
\hline \multicolumn{5}{|l|}{ Characteristics of treatment with tigecycline } \\
\hline Treatment line intended & & & & 0.045 \\
\hline Empiric & $38 / 73(52)$ & $35 / 83(42)$ & $73 / 156(47)$ & \\
\hline Documented $^{\mathrm{c}}$ & $27 / 73(37)$ & $45 / 83(54)$ & $72 / 156(46)$ & \\
\hline \multicolumn{5}{|l|}{ Reason for choosing tigecycline } \\
\hline Polymicrobial infection & $37 / 73(51)$ & $49 / 83(59)$ & $86 / 156(55)$ & 0.295 \\
\hline Multiresistant bacteria suspected/identified & $28 / 73(38)$ & $35 / 83(42)$ & $63 / 156(40)$ & 0.628 \\
\hline Renal failure & $7 / 73(10)$ & $21 / 83(25)$ & $28 / 156(18)$ & 0.011 \\
\hline Multiple site infection & $8 / 73(11)$ & $16 / 83(19)$ & $24 / 156(15)$ & 0.151 \\
\hline Failure of previous treatment & $6 / 73(8)$ & $13 / 83(16)$ & $19 / 156(12)$ & 0.156 \\
\hline Allergy/intolerance to another antibacterial agent & $9 / 73(12)$ & $6 / 83(7)$ & $15 / 156(10)$ & 0.281 \\
\hline Rescue treatment & $8 / 73(11)$ & $5 / 83(6)$ & $13 / 156(8)$ & 0.266 \\
\hline Other & $5 / 73(7)$ & $5 / 83(6)$ & $10 / 156(6)$ & 0.834 \\
\hline Loading dose of $100 \mathrm{mg}$ & $70 / 73(96)$ & $82 / 83(99)$ & $152 / 156(97)$ & 0.341 \\
\hline Maintenance dose of $50 \mathrm{mg}$ bid & $68 / 73(93)$ & $78 / 83(94)$ & $146 / 156(94)$ & 0.859 \\
\hline
\end{tabular}

Data are median values (range) or $n / N(\%)$ of patients, with a SOFA subscore of 3 or 4 (on a 0-4 scale)

$N=$ number of available data

$B M I$ body mass index, ICU intensive care unit, SAPS simplified

b SOFA subscore of 3 or 4 (on a $0-4$ scale); chronic renal failures acute physiology score, SOFA sequential organ failure assessment 
Table 2 Number (\%) of baseline isolates by sensitivity to tigecycline

\begin{tabular}{|c|c|c|c|}
\hline & Total isolates & Susceptible $^{\mathrm{a}}$ & Intermediate or resistant $\mathrm{t}^{\mathrm{a}}$ \\
\hline Total & $250(100)$ & $108(83.7)$ & $21(16.3)$ \\
\hline Aerobes & $221(88.4)$ & $104(83.2)$ & $21(16.8)$ \\
\hline Gram-positive cocci & $103(41.2)$ & $50(96.2)$ & $2(3.8)$ \\
\hline Enterococci & $51(20.4)$ & $29(93.5)$ & $2(6.5)$ \\
\hline Enterococcus faecalis & $16(6.4)$ & $6(85.7)$ & $1(14.3)$ \\
\hline Enterococcus faecium & $21(8.4)$ & $12(92.3)$ & $1(7.7)$ \\
\hline Staphylococci & $36(14.4)$ & $16(100)$ & \\
\hline Staphylococcus aureus & $20(8.0)$ & $10(100)$ & \\
\hline Streptococci & $16(6.4)$ & $5(100)$ & \\
\hline Gram-negative bacilli & $118(47.2)$ & $54(74.0)$ & $19(26.0)$ \\
\hline Enterobacteriaceae & 89 (35.6) & $41(74.5)$ & $14(25.5)$ \\
\hline Escherichia coli & 44 (17.6) & $23(95.8)$ & $1(4.2)$ \\
\hline Klebsiella spp. & $18(7.2)$ & $8(61.5)$ & $5(38.5)$ \\
\hline Enterobacter spp. & $14(5.6)$ & $8(72.7)$ & $3(27.3)$ \\
\hline Serratia spp. & $4(1.6)$ & $1(33.3)$ & $2(66.7)$ \\
\hline Citrobacter & $2(0.8)$ & $1(50.0)$ & $1(50.0)$ \\
\hline Proteus spp. & $6(2.4)$ & & $1(100)$ \\
\hline Morganella spp. & $1(0.4)$ & & $1(100)$ \\
\hline Non-fermenting Gram-negative bacilli & $15(6.0)$ & $5(50.0)$ & $5(50.0)$ \\
\hline Pseudomonas aeruginosa & $6(2.4)$ & & $1(100)$ \\
\hline Stenotrophomonas maltophilia & $8(3.2)$ & $5(62.5)$ & $3(37.5)$ \\
\hline Acinetobacter baumannii & $1(0.4)$ & & $1(100)$ \\
\hline Other Gram-negative strains & $14(5.6)$ & $8(100)$ & \\
\hline Anaerobes & $18(7.2)$ & $4(100)$ & \\
\hline Bacteroides fragilis & $6(2.4)$ & $1(100)$ & \\
\hline Other anaerobes & $12(4.8)$ & $3(100)$ & \\
\hline Pathogens, no further specified & $3(1.2)$ & & \\
\hline
\end{tabular}

${ }^{a}$ Percentage of isolates for which the sensitivity to tigecycline was known

difference between groups (64 vs. $65 \%$ for the $<70$ and $\geq 70$ years age groups, respectively, $P=0.906$; and 63 vs. $66 \%$ for the SOFA $<7$ and $\geq 7$ groups, respectively, $P=0.671)$. The aminoglycosides used were amikacin (17\% of all patients) and gentamicin (8\%). The most frequently used penicillin was piperacillin (combined with tazobactam, $11 \%$ ).

Tigecycline treatment was prematurely stopped in 66 $(42 \%)$ patients, without statistically significant difference according to the illness severity $(P=0.774)$. The reasons were resistant strain included $(n=11)$, clinical failure $(n=12)$, de-escalation $(n=20)$, death $(n=14)$, new infection $(n=4)$, persistent fever of unknown origin $(n=1)$, unjustified antibacterial agent change $(n=1)$ and/or shock probably not of infectious origin $(n=1)$. In the less severely ill patients, the most common reasons were de-escalation $(10 / 37,33 \%)$ and resistant strain $(n=8)$, whereas in the most severely ill patients they were death $(12 / 36,33 \%)$ and de-escalation $(n=10)$.

Adverse events were reported in 16 and $29 \%$ of the less and most severely ill patients, respectively ( $23 \%$ of total patients). Three adverse events were considered as probably/ definitely related to tigecycline: drug resistance $(n=1)$, drug inefficacy (death due to septic shock, $n=1$ ) and acute renal failure (patient cured with tigecycline, $n=1$ ). Irrespective of causality, serious adverse events (fatal or not) occurred in 10 and $23 \%$ of the less and most severely ill patients, respectively (17\% of total patients).

\section{Response to treatment}

The overall success rate was $60 \%[93 / 156,95 \% \mathrm{CI}$ (51-67)] at the end of treatment, and $53 \%[77 / 145,95 \%$ CI (45-61)] 7 days after the end of treatment (Table 3). The difference in success rates between the less and the most severely ill patients was significant at both time points $(P=0.005, P=0.001$, respectively). The success rate at the end of treatment for patients alive after the last tigecycline uptake was $65 \%$ [92/141, $95 \%$ CI (57-73)]. The causes of failure at the end of treatment are described in Table 3. Table 4 provides the success rates obtained in the patient subgroups of interest, 7 days after the end of treatment.

The success rate at 7 days after treatment was statistically significantly higher when tigecycline treatment duration was longer. In the whole cohort, the success rate was $70 \%$ with a treatment duration $>9$ days vs. $40 \%$ with a treatment duration $\leq 9$ days $(P<0.001)$. Similarly, it was 80 vs. $55 \%(P=0.097)$ respectively, in the less severely ill patients and 61 vs. $27 \%$, respectively, in the most severely ill patients $(P=0.008)$. Combination of another antibiotic with tigecycline did not markedly influence the success rate in the whole cohort, in the less and in the most severely ill patients (54 vs. $51 \%$; 67 vs. $64 \%$; 42 vs. $39 \%$, respectively).

A reduced rate, although not statistically significant, was observed with concomitant bacteraemia vs. without 


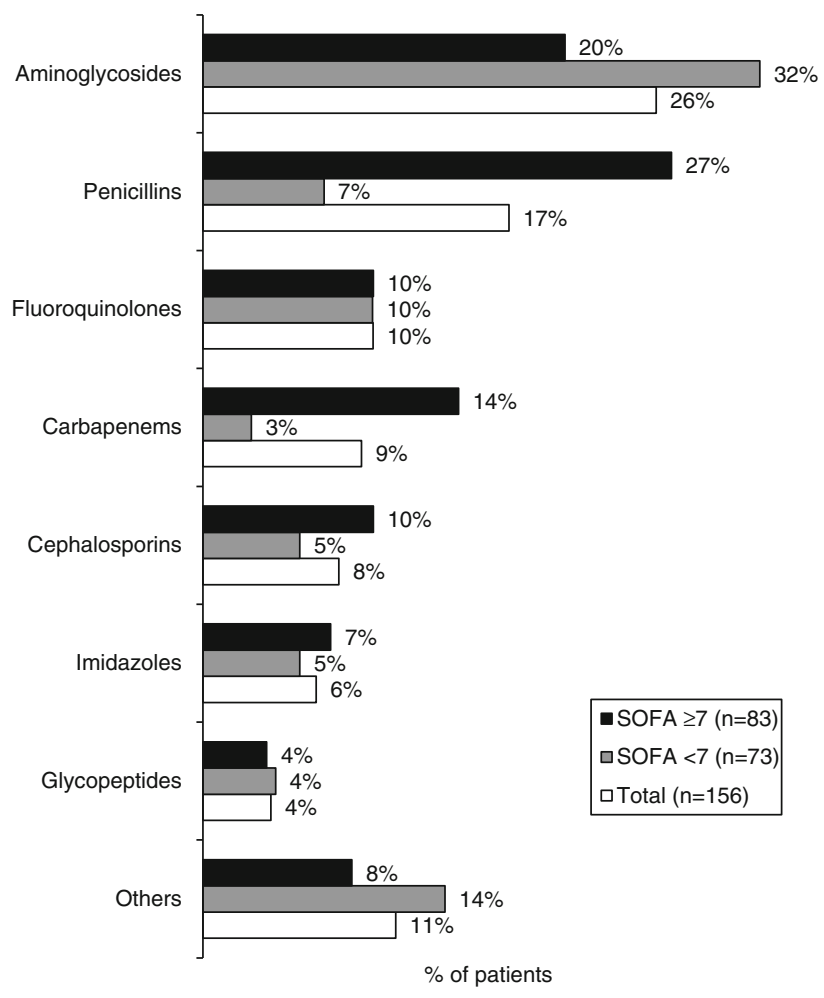

Fig. 1 Anti-infective agents combined with tigecycline bacteraemia, in the less (62 vs. $74 \%$ ) and in the most severely ill patients (33 vs. $54 \%$ ).

Univariate regressions identified two factors associated with failure of treatment at 7 days: the SOFA score, either expressed as increasing SD units $[\mathrm{OR}=1.72$, $95 \%$ CI $(1.20-2.50), \quad P=0.003] \quad$ or a score $\geq 7$ $[\mathrm{OR}=2.70,95 \% \mathrm{CI}(1.39-5.26), P=0.004]$, and BMI, either expressed as increasing SD units $[\mathrm{OR}=9.09$, $95 \%$ CI $(1.92-50), P=0.005]$ or a BMI $>35 \mathrm{~kg} / \mathrm{m}^{2}$ $[\mathrm{OR}=1.39,95 \%$ CI $(0.96-2.00), P=0.080]$. The factors associated with failure and identified using the multivariate analysis were an increasing SOFA score $[\mathrm{OR}=1.67,95 \% \mathrm{CI}(1.12-2.44), P=0.010]$ and $\mathrm{a}$ BMI $>35 \mathrm{~kg} / \mathrm{m}^{2} \quad[\mathrm{OR}=8.33,95 \%$ CI $\quad(1.82-33.33)$, $P=0.007]$. The sensitivity and specificity of this model were $94 \%$ [95\% CI (0.88-1.00)] and $37 \%$ [95\% CI $(0.25-0.49)]$, respectively.

\section{Survival}

Global survival at 28 days was $85 \%$ and no statistical difference was observed between age groups ( 87 vs. $80 \%$ for the $<70$ and $\geq 70$ years age groups, respectively, $P=0.408$ ). Survival at day 28 was higher in patients with a BMI $\leq 35 \mathrm{~kg} / \mathrm{m}^{2}$ than with a BMI $>35 \mathrm{~kg} / \mathrm{m}^{2}$ (87 vs. $63 \%$,

Table 3 Response to treatment with tigecycline

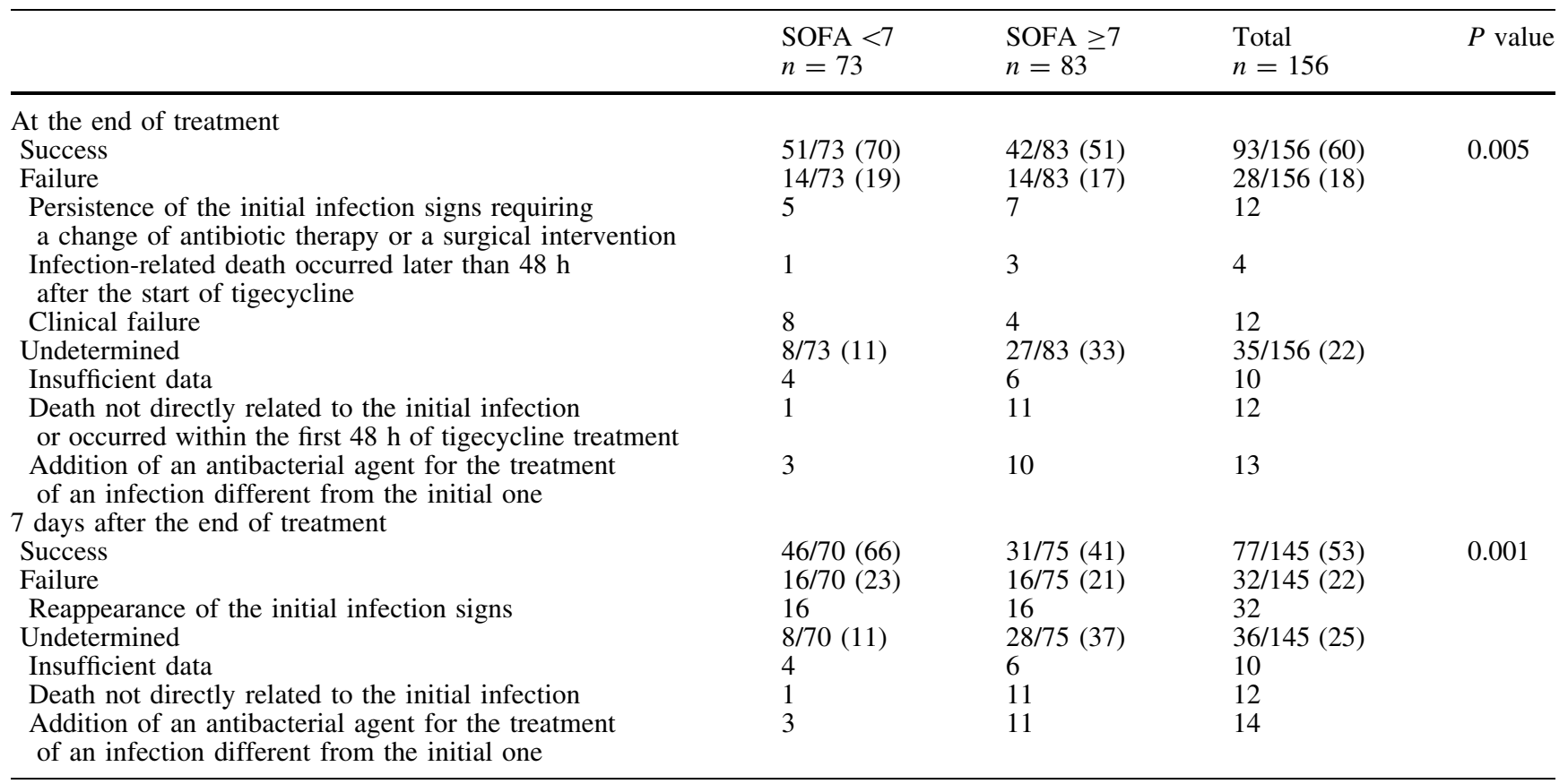

Data are $n / N(\%)$ of patients, with $N=$ number of available data

SOFA sequential organ failure assessment 
Table 4 Success rate according to the major characteristics of patients, infections and tigecycline treatment

\begin{tabular}{|c|c|c|}
\hline Characteristics & $\begin{array}{l}\text { Success rate } 7 \text { days after } \\
\text { the end of tigecycline }\end{array}$ & $P$ value \\
\hline \multicolumn{3}{|l|}{ Patient } \\
\hline Age $<70$ years & $50 / 94(53)$ & 0.937 \\
\hline Age $\geq 70$ years & $27 / 51(53)$ & \\
\hline Not immunosuppressed & $53 / 94(56)$ & 0.555 \\
\hline Immunosuppressed & 24/51 (47) & \\
\hline BMI $\leq 35 \mathrm{~kg} / \mathrm{m}^{2}$ & $65 / 116(56)$ & $<0.001$ \\
\hline BMI $>35 \mathrm{~kg} / \mathrm{m}^{2}$ & 2/16 (13) & \\
\hline \multicolumn{3}{|l|}{ Localisation of infection } \\
\hline cSSTI & $17 / 27(63)$ & \\
\hline cIAI & $44 / 82(54)$ & \\
\hline Pulmonary infection & $17 / 37(46)$ & \\
\hline No concomitant bacteraemia & $66 / 118(56)$ & 0.492 \\
\hline Concomitant bacteraemia & 8/17 (47) & \\
\hline \multicolumn{3}{|l|}{ Species at start of treatment } \\
\hline Gram-positive cocci & $31 / 64(48)$ & \\
\hline Enterobacteria & $37 / 66(56)$ & \\
\hline Anaerobes & $10 / 11(91)$ & \\
\hline Other bacteria & $14 / 25(56)$ & \\
\hline \multicolumn{3}{|l|}{ Tigecycline treatment } \\
\hline Duration $\leq 9$ days & $34 / 84(40)$ & $<0.001$ \\
\hline Duration $>9$ days & 43/61 (70) & \\
\hline Monotherapy & $23 / 45(51)$ & 0.747 \\
\hline Combination & $54 / 100(54)$ & \\
\hline Empiric therapy & 38/70 (54) & 0.783 \\
\hline Documented therapy & $39 / 75(52)$ & \\
\hline
\end{tabular}

Data are $n / N(\%)$ of patients, with $N=$ number of available data cSSTI complicated skin and soft tissue infection, cIAI complicated intra-abdominal infection

$P=0.003)$ and statistically significantly higher in the less than in the most severely ill patients (96 vs. $75 \%$, $P<0.001$ ) (electronic supplementary material). Moreover, patients receiving catecholamines treatment had a statistically significant lower survival rate than those not treated with catecholamines ( 75 vs. $94 \%, P=0.001$ ). Survival at day 28 was 86,93 and $80 \%$ for the patients initially suffering from IAI, SSTI and other infections, respectively.

\section{Discussion}

The efficacy of tigecycline versus other antimicrobial agents for the treatment of cSSTI [1-3] and cIAI [4-7, 27] has been evidenced in several RCTs, demonstrating that tigecycline was as efficacious as the comparators in treating infections, with a comparable safety profile. Three recent meta-analyses evaluating the published data from available RCTs also found no statistically significant difference in treatment success between cIAI patients treated with tigecycline and those treated with comparators [28-30]. However, in both cSSTI and cIAI trials, severe cases were usually excluded from the protocol, leading to insignificant information about these particular cases.

Recently, the US Food and Drug Administration (FDA) and the European Medicines Agency (EMA) issued a warning regarding the risk of increased mortality in patients treated with tigecycline, observed in the clinical trials $[31,32]$. In all phase III and IV (cSSTI and cIAI) studies, death occurred in $2.4 \%(54 / 2,216)$ of patients receiving tigecycline and in $1.7 \%(37 / 2,206)$ of patients receiving comparator drugs [33]. A number of meta-analyses also reported higher all-cause mortality in patients treated with tigecycline versus comparators in RCTs [28-30, 34, 35]. Taking into account these findings, the EMA Committee for Medicinal Products for Human Use concluded that tigecycline benefits continue to outweigh its risks, but recommended modifications in product information to ensure an appropriate use, by making prescribers aware of the observed increased mortality risk. In addition, they issued a recommendation stating that tigecycline should be used only when other antibiotics are known or suspected to be not suitable [33].

However, clinical trials concerning critically ill patients' management are limited. A few large observational studies have been set up to determine the outcomes of ICU tigecycline-treated patients in clinical practice. The success rates obtained in the current study are in line with those reported in previous registries $[13-15,18]$ and in the European registry [17-19]. Interestingly, the success rate is also comparable to those reported in RCTs assessing the efficacy of other antibiotics in the ICU setting [36].

RCTs in contrast to registries generally do not reflect the clinical practice and do not represent real-life patients because of stringent selection criteria. This point is of interest particularly in ICU patients, for whom a limited number of trials are conducted only in selected indications. In addition, the evaluation endpoints used here were selected to ensure that the physician's concerns were respected and obviously do not favour the product.

The tigecycline dosage used in this study stands in the conventional range (100 mg daily) in 93-94\% of the cases. Interestingly, a relatively satisfactory success rate was reported in pulmonary infection patients. Similarly to other antibiotic drugs [37], concerns have been raised about the best dose for tigecycline, especially for treatment of pulmonary infections. Recent publications suggest a potential benefit of high dose tigecycline ( $200 \mathrm{mg}$ daily) in severe/ difficult-to-treat infections [38]. Effectiveness and safety of this policy without adding new risk factors for potentially resistant bacteria remain to be confirmed [39].

The never-ending debate on bacteriostatic drugs use for treatment of serious infections was re-triggered with the launch of tigecycline [40]. In many ICUs across the world, physicians dare to prescribe this bacteriostatic agent without having the feeling of putting their patients in jeopardy [13-15]. This point is particularly relevant in patients receiving a monotherapy as a first-line treatment. We, like others, report good results in monotherapy in more than half of patients receiving tigecycline. In contrast to other countries, tigecycline seems to be used in France mainly in combination with agents directed 
particularly against Gram-negative microorganisms, and the preferred indications are those of the marketing authorisations. This finding was also reported in the European registries [17-19]. For instance, in a severe ICU population in Germany, tigecycline was also used mostly in combination (76\%), but the therapy frequently targeted Gram-positive cocci (including enterococci) possibly because of the high frequency of vancomycinresistant strains. In Latin American countries, the tigecycline use in off-label indications appears to be important [41].

Finally, there were no serious adverse events requiring tigecycline discontinuation, and few tigecycline-related adverse events were reported. It is important to note that tigecycline administration in severe ICU patients, particularly in those with multiple organ failure, raised no safety concerns.

Like all observational studies, the limitations of our study included the lack of a control group and randomisation. However, our results contribute to the knowledge about tigecycline use in severely ill patients, a fragile population lacking clinical data. It is interesting that no increased mortality was observed in the cIAI and cSSTI tigecycline-treated patients, as observed in the five different European registries.

From our experience, tigecycline could be proposed as an empiric therapy in low severity cases, non-immunosuppressed or non-bacteraemic infections. In severe infections, immunosuppressed, bacteraemic or obese patients, its use should be cautiously considered, and restricted to documented therapy based on susceptibility testing in difficult-to-treat infections. Other options should be considered for suspected $P$. aeruginosa infections $[42,43]$.

\section{Conclusions}

In this ICU population treated with tigecycline, the success rates were comparable to those obtained in clinical studies analysing severe infections. In contrast to its use in other countries, tigecycline appears to be used mainly in combination with agents directed particularly against Gram-negative microorganisms.

Acknowledgments The study was sponsored by Pfizer. We are very grateful to all investigators for participating in this study. We also thank Axonal (Nanterre, France) for study logistics, data management and statistical analysis. We thank ClinSearch (Bagneux, France) who provided medical writing services on behalf of Pfizer. The results were presented in part at 2012 ESICM congress Lisbon.

Conflicts of interest P.M. has received research grant support and consultancy and/or speaker fees from Astellas, AstraZeneca, Gilead, Merck Sharp \& Dohme, Pfizer and The Medicine Company. H.D. has received research grant support from Pfizer and consultancy and/or speaker fees from Astellas, Merck Sharp \& Dohme and Pfizer. J.P.B. has received consultancy and/or speakers fees from Astellas, Astra-Zeneca, Novartis and Pfizer. P.B. is an employee of Pfizer.

Open Access This article is distributed under the terms of the Creative Commons Attribution Noncommercial License which permits any noncommercial use, distribution, and reproduction in any medium, provided the original author(s) and the source are credited.

\section{Appendix: List of investigators (France)}

Professors/Drs Airapetian (Amiens), Arich (Nîmes), Martin (Marseille), Asehnoune (Nantes), Auboyer (St Priest en Jarez), Bazin (Clermont-Ferrand), Bonneil (Pau), Bruder (Marseille), Bruneel (Le Chesnay), Desmard (Paris), Duranteau (Le Kremlin-Bicêtre), Georges (Toulouse), Ichai (Nice), Jaber (Montpellier), Payen (La Tronche), Perrigault (Montpellier), Plantefeve (Argenteuil), Pottecher (Strasbourg), Poussel (Laquenexy), Riu Poulenc (Toulouse), Samain (Besançon), Schoeffler (Clermont-Ferrand), Seguin (Rennes), Sztark (Bordeaux), Veber (Rouen), Winnock (Bordeaux).

\section{References}

1. Breedt J, Teras J, Gardovskis J, Maritz FJ, Vaasna T, Ross DP, Gioud-Paquet M, Dartois N, Ellis-Grosse EJ, Loh E et al (2005) Safety and efficacy of tigecycline in treatment of skin and skin structure infections: results of a doubleblind phase 3 comparison study with vancomycin-aztreonam. Antimicrob Agents Chemother 49:4658-4666. doi: 10.1128/AAC.49.11.4658-4666.2005
2. Ellis-Grosse EJ, Babinchak T, Dartois N, Rose G, Loh E et al (2005) The efficacy and safety of tigecycline in the treatment of skin and skin-structure infections: results of 2 double-blind phase 3 comparison studies with vancomycin-aztreonam. Clin Infect Dis 41(Suppl 5):S341-S353. doi: $10.1086 / 431675$
3. Sacchidanand S, Penn RL, Embil JM, Campos ME, Curcio D, Ellis-Grosse E, Loh E, Rose G (2005) Efficacy and safety of tigecycline monotherapy compared with vancomycin plus aztreonam in patients with complicated skin and skin structure infections: results from a phase 3 , randomized, double-blind trial. Int $\mathbf{J}$ Infect Dis 9:251-261. doi:10.1016/j.ijid. 2005.05.003 
4. Babinchak T, Ellis-Grosse E, Dartois N, Rose GM, Loh E et al (2005) The efficacy and safety of tigecycline for the treatment of complicated intraabdominal infections: analysis of pooled clinical trial data. Clin Infect Dis 41(Suppl 5):S354-S367. doi: $10.1086 / 431676$

5. Fomin P, Beuran M, Gradauskas A, Barauskas G, Datsenko A, Dartois N, Ellis-Grosse E, Loh E et al (2005) Tigecycline is efficacious in the treatment of complicated intraabdominal infections. Int J Surg 3:35-47. doi:10.1016/j.ijsu.2005.03.011

6. Oliva ME, Rekha A, Yellin A, Pasternak J, Campos M, Rose GM, Babinchak T, Ellis-Grosse EJ, Loh E et al (2005) A multicenter trial of the efficacy and safety of tigecycline versus imipenem/cilastatin in patients with complicated intra-abdominal infections [Study ID Numbers: 3074A1-301-WW; ClinicalTrials.gov Identifier:

NCT00081744]. BMC Infect Dis 5:88. doi:10.1186/1471-2334-5-88

7. Towfigh S, Pasternak J, Poirier A, Leister H, Babinchak T (2010) A multicentre, open-label, randomized comparative study of tigecycline versus ceftriaxone sodium plus metronidazole for the treatment of hospitalized subjects with complicated intraabdominal infections. Clin Microbiol Infect 16:1274-1281. doi: 10.1111/j.1469-0691.2010.03122.x

8. Bergallo C, Jasovich A, Teglia O, Oliva ME, Lentnek A, de Wouters L, Zlocowski JC, Dukart G, Cooper A, Mallick R et al (2009) Safety and efficacy of intravenous tigecycline in treatment of community-acquired pneumonia: results from a double-blind randomized phase 3 comparison study with levofloxacin. Diagn Microbiol Infect Dis 63:52-61. doi: 10.1016/j.diagmicrobio.2008.09.001

9. Freire AT, Melnyk V, Kim MJ, Datsenko O, Dzyublik O, Glumcher F, Chuang YC, Maroko RT, Dukart G, Cooper CA, Korth-Bradley JM, Dartois $\mathrm{N}$, Gandjini H et al (2010) Comparison of tigecycline with imipenem/cilastatin for the treatment of hospital-acquired pneumonia. Diagn Microbiol Infect Dis 68:140-151. doi:

10.1016/j.diagmicrobio.2010.05.012

10. Tanaseanu C, Bergallo C, Teglia O, Jasovich A, Oliva ME, Dukart G, Dartois N, Cooper CA, Gandjini H, Mallick R et al (2008) Integrated results of 2 phase 3 studies comparing tigecycline and levofloxacin in community-acquired pneumonia. Diagn Microbiol Infect Dis 61:329-338. doi: 10.1016/j.diagmicrobio.2008.04.009
11. Florescu I, Beuran M, Dimov R, Razbadauskas A, Bochan M, Fichev G, Dukart G, Babinchak T, Cooper CA, Ellis-Grosse EJ, Dartois N, Gandjini H et al (2008) Efficacy and safety of tigecycline compared with vancomycin or linezolid for treatment of serious infections with methicillin-resistant Staphylococcus aureus or vancomycinresistant enterococci: a phase 3 , multicentre, double-blind, randomized study. J Antimicrob Chemother 62(Suppl 1):i17-i28. doi: 10.1093/jac/dkn250

12. Vasilev K, Reshedko G, Orasan R, Sanchez M, Teras J, Babinchak T, Dukart G, Cooper A, Dartois N, Gandjini H, Orrico R, Ellis-Grosse E et al (2008) A phase 3, open-label, noncomparative study of tigecycline in the treatment of patients with selected serious infections due to resistant Gram-negative organisms including Enterobacter species, Acinetobacter baumannii and Klebsiella pneumoniae. J Antimicrob Chemother 62(Suppl 1):i29-i40. doi:10.1093/jac/dkn249

13. Bassetti M, Nicolini L, Repetto E, Righi E, Del Bono V, Viscoli C (2010) Tigecycline use in serious nosocomial infections: a drug use evaluation. BMC Infect Dis 10:287. doi: 10.1186/1471-2334-10-287

14. Curcio D, Fernandez F, Cane A, Barcelona L, Stamboulian D (2008) Indications of a new antibiotic in clinical practice: results of the tigecycline initial use registry. Braz $\mathrm{J}$ Infect Dis 12:198-201

15. Swoboda S, Ober M, Hainer C, Lichtenstern C, Seiler C, Wendt C, Hoppe-Tichy T, Buchler M, Weigand MA (2008) Tigecycline for the treatment of patients with severe sepsis or septic shock: a drug use evaluation in a surgical intensive care unit.

J Antimicrob Chemother 61:729-733. doi:10.1093/jac/dkm541

16. Gardiner D, Dukart G, Cooper A, Babinchak T (2010) Safety and efficacy of intravenous tigecycline in subjects with secondary bacteremia: pooled results from 8 phase III clinical trials. Clin Infect Dis 50:229-238. doi: 10.1086/648720

17. Bassetti M, Eckmann C, Bodmann KF, Dupont H, Heizmann WR, Montravers P, Guirao X, Capparella MR, Simoneau D, Sanchez Garcia M (2013) Prescription behaviours for tigecycline in real-life clinical practice from five European observational studies. J Antimicrob Chemother 68(Suppl 2):ii5-ii14. doi:10.1093/jac/dkt140
18. Eckmann C, Montravers P, Bassetti M, Bodmann KF, Heizmann WR, Sanchez Garcia M, Guirao X, Capparella MR, Simoneau D, Dupont H (2013) Efficacy of tigecycline for the treatment of complicated intra-abdominal infections in real-life clinical practice from five European observational studies. J Antimicrob Chemother 68(Suppl 2):ii25-ii35. doi:10.1093/jac/dkt142

19. Montravers P, Bassetti M, Dupont H, Eckmann C, Heizmann WR, Guirao X, Garcia MS, Capparella MR, Simoneau D, Bodmann KF (2013) Efficacy of tigecycline for the treatment of complicated skin and soft-tissue infections in real-life clinical practice from five European observational studies. J Antimicrob Chemother 68(Suppl 2):ii15-ii24. doi: 10.1093/jac/dkt141

20. Heizmann WR, Dupont H, Montravers P, Guirao X, Eckmann C, Bassetti M, Garcia MS, Capparella MR, Simoneau D, Bodmann KF (2013) Resistance mechanisms and epidemiology of multiresistant pathogens in Europe and efficacy of tigecycline in observational studies. J Antimicrob Chemother 68(Suppl 2):ii45-ii55. doi: 10.1093/jac/dkt144

21. Guirao X, Sanchez Garcia M, Bassetti M, Bodmann KF, Dupont H, Montravers P, Heizmann WR, Capparella MR, Simoneau D, Eckmann C (2013) Safety and tolerability of tigecycline for the treatment of complicated skin and soft-tissue and intra-abdominal infections: an analysis based on five European observational studies. J Antimicrob Chemother 68(Suppl 2):ii37-ii44. doi: 10.1093/jac/dkt143

22. McCabe W, Jackson G (1962) Gramnegative bacteremia: I Etiology and ecology. Arch Intern Med 110:847-855

23. Pugh RN, Murray-Lyon IM, Dawson JL, Pietroni MC, Williams R (1973) Transection of the oesophagus for bleeding oesophageal varices. Br J Surg 60:646-649

24. Le Gall JR, Lemeshow S, Saulnier F (1993) A new simplified acute physiology score (SAPS II) based on a European/North American multicenter study. JAMA 270:2957-2963

25. Vincent JL, Moreno R, Takala J, Willatts S, De Mendonca A, Bruining H, Reinhart CK, Suter PM, Thijs LG (1996) The SOFA (sepsis-related organ failure assessment) score to describe organ dysfunction/failure. On behalf of the Working Group on Sepsis-Related Problems of the European Society of Intensive Care Medicine. Intensive Care Med 22:707-710 
26. Jaeschke R, Guyatt G, Sackett DL (1994) Users' guides to the medical literature. III. How to use an article about a diagnostic test. A. Are the results of the study valid? EvidenceBased Medicine Working Group. JAMA 271:389-391

27. Chen Z, Wu J, Zhang Y, Wei J, Leng X, Bi J, Li R, Yan L, Quan Z, Chen X, Yu Y, Wu Z, Liu D, Ma X, Maroko R, Cooper A (2010) Efficacy and safety of tigecycline monotherapy vs. imipenem/ cilastatin in Chinese patients with complicated intra-abdominal infections: a randomized controlled trial. BMC Infect Dis 10:217. doi: 10.1186/1471-2334-10-217

28. Cai Y, Wang R, Liang B, Bai N, Liu Y (2011) Systematic review and metaanalysis of the effectiveness and safety of tigecycline for treatment of infectious disease. Antimicrob Agents Chemother 55:1162-1172. doi: 10.1128/AAC.01402-10

29. Tasina E, Haidich AB, Kokkali S, Arvanitidou M (2011) Efficacy and safety of tigecycline for the treatment of infectious diseases: a meta-analysis. Lancet Infect Dis 11:834-844. doi: 10.1016/S1473-3099(11)70177-3

30. Vardakas KZ, Rafailidis PI, Falagas ME (2012) Effectiveness and safety of tigecycline: focus on use for approved indications. Clin Infect Dis 54:1672-1674. doi:10.1093/cid/cis239

31. FDA (2010) http://www.fda.gov/ drugs/drugsafety/ucm224370.htm. Accessed 1 Jan 2014

32. EMA (2011) http://www. ema.europa.eu/docs/en_GB/ document_library/Medicine_QA/ human/000644/WC500102228.pdf. Accessed 1 Jan 2014
33. EMA (2012) http://www.ema.europa. eu/docs/en_GB/document_library/ EPAR_-_Summary_for_the_public/ human/000644/WC500044509.pdf. Accessed 1 Jan 2014

34. Prasad P, Sun J, Danner RL, Natanson C (2012) Excess deaths associated with tigecycline after approval based on noninferiority trials. Clin Infect Dis 54:1699-1709. doi:10.1093/cid/cis270

35. Yahav D, Lador A, Paul M, Leibovici L (2011) Efficacy and safety of tigecycline: a systematic review and meta-analysis. J Antimicrob Chemother 66:1963-1971. doi:10.1093/jac/dkr242

36. Chastre J, Wunderink R, Prokocimer P, Lee M, Kaniga K, Friedland I (2008) Efficacy and safety of intravenous infusion of doripenem versus imipenem in ventilator-associated pneumonia: a multicenter, randomized study. Crit Care Med 36:1089-1096. doi: 10.1097/CCM.0b013e3181691b99

37. Pletz MW, Lipman J (2013) Clinical measures for increased creatinine clearances and suboptimal antibiotic dosing. Intensive Care Med 39:1322-1324. doi: 10.1007/s00134-013-2918-8

38. Falagas ME, Vardakas KZ, Tsiveriotis KP, Triarides NA, Tansarli GS (2014) Effectiveness and safety of high-dose tigecycline-containing regimens for the treatment of severe bacterial infections. Int $\mathbf{J}$ Antimicrob Agents. doi: 10.1016/j.ijantimicag.2014.01.006

39. Paiva JA (2013) Adding risk factors for potentially resistant pathogens, increasing antibiotic pressure and risk creating the "untreatable bacteria": time to change direction. Intensive Care Med 39:779-781. doi: 10.1007/s00134-012-2811-x
40. Pankey GA, Sabath LD (2004) Clinical relevance of bacteriostatic versus bactericidal mechanisms of action in the treatment of Gram-positive bacterial infections. Clin Infect Dis 38:864-870. doi:10.1086/381972

41. Curcio D, Vargas SW, Ugarte Ubiergo S, Varon F, Rojas Suarez J, Paz Chavez C, Curiale A et al (2011) Tigecycline treatment of critically ill patients: the LatinUser experience. Curr Clin Pharmacol 6:18-25

42. Dellinger RP, Levy MM, Rhodes A, Annane D, Gerlach H, Opal SM, Sevransky JE, Sprung CL, Douglas IS, Jaeschke R, Osborn TM, Nunnally ME, Townsend SR, Reinhart K, Kleinpell RM, Angus DC, Deutschman CS, Machado FR, Rubenfeld GD, Webb S, Beale RJ, Vincent JL, Moreno R et al (2013) Surviving Sepsis Campaign: international guidelines for management of severe sepsis and septic shock, 2012. Intensive Care Med 39:165-228. doi: 10.1007/s00134-012-2769-8

43. Tumbarello M, De Pascale G, Trecarichi EM, Spanu T, Antonicelli F, Maviglia R, Pennisi MA, Bello G, Antonelli M (2013) Clinical outcomes of Pseudomonas aeruginosa pneumonia in intensive care unit patients. Intensive Care Med 39:682-692. doi: 10.1007/s00134-013-2828-9 